\title{
La emergencia del relato ante la inminencia del acontecimiento
}

Mauricio Barría Jara ${ }^{1}$

Escribir sobre performance resulta desde ya una situación paradójica. No solo por el desfase evidente entre discurso y evento al que alude esta relación, sino principalmente por la vaguedad que supone la noción misma de esta práctica artística. No han sido pocos los esfuerzos por tratar de determinar su especificidad y encontrar su lugar al interior del sistema de las artes. Pero, es quizá esta falta de cota, esta excesiva amplitud lo que la haga especialmente interesante, pues, de alguna manera, este exceso operaría como un líquido de contraste que exacerba las tensiones que el propio arte contemporáneo ha pretendido poner en obra los últimos cincuenta años. Desde este punto de vista la performance constituiría la clavija o síntoma privilegiado e insoslayable para comprender las cuestiones que afligen, al arte de hoy: las querellas sobre la representación; las relaciones entre obra, circuitos y espectacularidad; el fin del objeto y la emergencia de los procesos, y por cierto, lo más gravitante: la emergencia del acontecimiento ${ }^{2}$. Pero tal vez, uno de los asuntos de mayor gravedad que la performance devela sea la pregunta por el rol del texto teórico y crítico en la escena artística contemporánea. ¿Qué hace la teoría respecto a una performance? Esta interrogante claramente se torna urgente ante un tipo de cosa que consiste en suceder. Ante ello: ¿la labor de la teoría es comentar, acaso servir de registro crítico; de instalar la acción en los circuitos y las lógicas históricas y comerciales o debe explicar, es decir, ser el nexo entre el público y la obra? Pienso que es el juego o el jugar lo propio de una escritura teórica que pretenda abordar la cuestión de la performance. Su política debe ser no la de la inscripción sino la del flujo y la diseminación. Ante la enorme proliferación de literatura sobre el tema, que ha invadido nuestro campo cultural, especialmente en estos últimos años, se hace difícil imaginar que en relación a estos temas sea posible decir algo definitivo, incluso
1.

Doutor em Filosofia pela Universidade do Chile e Professor do Departamento de Teatro da Universidade do Chile.

2.

Aquello que Fischer-Lichte ha denominado con fortuna "giro performativo". Cf. Fischer-Lichte, Erika, Estética de lo performativo, Madrid, Abada: 2011 
más, cuando la índole propia del objeto-evento "performance" pareciera consistir en ser intersticial (liminal) o nómade, es decir, un categoría en permanente tránsito y desplazamiento.

Hemos experimentado en los últimos años una cierta efervescencia de las prácticas de performance en el medio artístico chileno. La importante cantidad de cultores de esta práctica se ha ido incrementando según aparecen encuentros y festivales de performance en Santiago y en Regiones. A esta cantidad de artistas se suma la enorme variedad de trabajos que caen hoy bajo la categoría de performance, con el consiguiente cuestionamiento acerca de la pertinencia de esta denominación. Esta variedad viene por sobre todo a complicar el trabajo de una crítica que deseara pensar el problema de la recepción. ¿Qué es lo que se espera que un público determinado recepcione de un tipo de obra como esta? ¿Está condenada la performance a ser un tipo de manifestación de elite, o por el contrario un tipo de fenómeno tan abierto que dentro de ella cabría cualquier cosa? ¿Es posible configurar una hermenéutica de la acción, es decir, criterios para el análisis de algo que no es un estado sino que un devenir? ¿Acaso estos criterios están determinados por el contexto cultural? ¿Si esto fuera así, cómo este contexto modifica la recepción de la obra?

Cuestiones que no podemos pretender resolver, incluso, porque de lo que se trate sea de no resolverlas. Sin embargo, no podemos soslayar. En esto radica, a mi juicio, el mérito de la presente colección de ensayos. A través de su lectura podremos ir identificando y caracterizando algunas de las operaciones que, a mi juicio, son las que efectúa la performance y que responden a una interrogante muy precisa: ¿Qué hace una performance?

Lo que pareciera quedar en claro es que Performance no podría pretender convertirse en un objeto, en una disciplina o en un campo determinado de trabajo, sin que su peculiaridad transitiva no sufriera una traición. Parece ser lo propio de performance su constante deslocalización, y en tanto actividad, práctica o proceso uno tal que lleva a cabo o trata de desfondar, dislocar o agotar la identidad. Muchos verbos para sintomatizar la imposibilidad de atrapar en las palabras el acontecimiento. En este sentido performance es un desplazamiento y en el campo del arte, a pesar de que podemos reconocer una cierta práctica artística denominada así por la crítica de arte norteamericana de los 70 , su identificación es siempre una acción fallida. Este carácter nómade como lo hemos llamado más arriba es lo que se conoce como liminalidad. Si performance es un concepto umbral ${ }^{3}$, en cuanto nombra la posibilidad de desplazamiento de las fronteras disciplinarias y con ello disloca el tramado sistémico de esto disciplinario, entonces la performance como práctica artística consiste en
3.

Fischer-Lichte, Erika,

"Experiencia estética como experiencia umbral", traducción de Andrés Grumann (inédito). 
la producción de liminalidad, vale decir su efecto consiste en producir situaciones umbrales o liminales.

Como sabemos el concepto de liminalidad proviene de la antropología del ritual, y describe el estado intersticial por el que atraviesan los sujetos en una ritual de pasaje, posterior al haber sido separados de la comunidad y anterior a su reintegración en la misma. La lectura de Van Gennep enfatizo la dimensión espacial de la liminalidad en la metáfora del umbral o pórtico. De acuerdo a este énfasis el estado liminal carecía de real significación pues, en tanto umbral, era una situación que solo hallaba su sentido en referencia a los momentos semánticamente densos porque permanentes del ritual, a diferencia de lo liminal marcado por la transitoriedad. Bajo este paradigma, en definitiva textocéntrico, un umbral era simplemente lo para ser atravesado y abandonado. Sin embargo, la interpretación de Turner relevó la dimensión temporal que este intersticio suponía, poniendo el énfasis en la transitoriedad que definía al umbral o la frontera. Más precisamente, el umbral no es una metáfora que determina solamente relaciones espaciales, el umbral es también temporal, una manera en que sucede el tiempo y la experiencia de esa duración. Lo liminal no será pues un estado de alguna especie ni una simple línea divisoria para ser simplemente traspasada, será un lapso de tiempo en el que sucederán una serie de acontecimientos gravitantes para la vida de esa comunidad. En palabras de Turner ${ }^{4}$, durante los períodos liminales, los novicios son asociados a imágenes de muerte y nacimiento. No se les considera ni vivos ni muertos y están, a su vez, tanto vivos como muertos. Se encuentra en un entre lo sagrado y lo profano, que Turner lo plantea como un estado "interestructural" (betwixt in between). Desde este punto de vista la liminalidad sería el intersticio estructural en el que se suspende la propia estructura cultural que configura a los individuos según posiciones, roles y estatus sociales. Es decir, sería una suspensión o interrupción de las representaciones sociales que constituyen la identidad cultural de un sujeto. "un interfaz temporal cuyas propiedades invierten parcialmente aquellas propiedades del orden ya consolidado que constituye algún específico "cosmos" cultural. (Turner, 1973: 41) Sin embrago, Los alcances de la liminalidad no se limitan entonces a la sola interrupción momentánea de las representaciones que configuran al individuo como un sujeto social, estructuralmente hablando, la liminalidad irradia a la vasta zona del juego social en la que la comunidad entera ingresaría, porque en definitiva al ser arrancados los neófitos de sus posiciones estructurales (valores, normas, sentimientos y técnicas) son despojados de los pensamientos y hábitos de conducta asociados a éstos, por consiguiente, dirá Turner (1973): "los
4.

Cf. Turner, Víctor, Simbolismo y ritual, Lima, Pontificia Universidad Católica del Perú, 1973 
neófitos son alternativamente forzados y estimulados a pensar sobre su sociedad, su cosmos y sobre los poderes que los crean y los sostienen. La liminalidad puede ser parcialmente descrita como una etapa de reflexión. En ella, las ideas, sentimientos y hechos que hasta aquí eran aceptados inconcientemente por el neófito, son reducidos a sus elementos constituyentes." (68).

Para Turner la liminalidad sería entonces, aquella dimensión de la vida social en que se juega con las posibilidades combinatorias de los símbolos culturales para producir las transformaciones o permutaciones que permiten la resolución de conflictos generados por las propias reglas o patrones operantes, especialmente a nivel de las relaciones sociales.

Definida así, una performance de arte cabría entenderla como un dispositivo de producción de liminalidad, en otras palabras, una acción que consistiría en suspender o interrumpir el continuum de la representación (aquello sobre lo que se sostiene la cotidianidad) de manera de generar una instancia de transformación. La idea de interrupción del continuum en la medida que enfatiza su condición de cambio transitorio es posible pensarla como una falla ${ }^{5}$. En este sentido la performance consiste en fallar, en producir una falla y por eso podemos hablar también de recursos performativos ${ }^{6}$ como aquellos que tienden a la suspensión de la representación (del relato), o a su alteración o que llevan al límite los recursos de la representación al tensionar ésta con el acontecimiento, al generar una inminencia de la falla. Entonces una performance sería la puesta en obra/juego del umbral, y no solamente un concepto con las característica de lo-umbral, en lo que umbral deja de ser una metáfora exclusivamente espacial para rescatar su dimensión temporal. Desde una dimensión epistemológica performance o liminalidad significa someter al principio de identidad a su propia disolución, alteración o crisis, develándolo paradójicamente como un acontecimiento instaurador, pero al mismo tiempo transitorio, es decir, que se cancela al pretender reproducirse.

Lo que se fue develando entonces, es que si la performance llevaba a un límite la representación sin clausurarla, haciendo suceder una zona intersticial entre vivo y ficticio, entre presencia y mimesis, aquello que la performance alteraba ante todo, era ese aspecto de la representación que singularizaba a toda obra escénica o arte de acción: el modo en que se organiza la secuencia de acciones lo que hemos llamado en términos amplios: el relato. En efecto, es posible sostener que una de las cosas que ha provocado el ingente desarrollo de la performance es la de tornar urgente la pregunta por la relación entre experiencia y relato: en una época en la que vivimos la catástrofe de la experiencia (según la tesis de Benjamin) y como si el fin de la
5.

Fallar significa la fractura del programa premeditado que ejecuta un relato bajo un paradigma orgánico: el error que pone de manifiesto la costura del relato y al mismo tiempo desenmascara su falsa impostura de poder y eficiencia. La falla como el accidente nos instala en la experiencia radical del suceder, es la sorpresa ante lo inesperado o no calculado, y a veces ante lo insoportable. Por eso fallar también nos recuerda la idea de encuentro fallido que según Lacan es el modo en que nos relacionamos con lo Real. Lo fallido en este caso produce un quiasmo, la abertura, vacío o falta que define nuestra experiencia con lo Real. (cf. mi texto La intensidad de la falla, en este mismo volumen)

6.

Diana Taylor propone el uso de "performático" sobre "performativo" pues el segundo estaría todavía ligado al origen lingüístico y legal que le dio origen. Al respecto véase, TAYLOR, Diana, The archive and the repertoire, Durham, Duke UniversityPress: 2003: p.16 ss. Aunque las razones de Taylor son más que atendibles en el conjunto de ensayos que conforman este volumen hemos optado por el adjetivo "performativo" en el sentido que Taylor plantea el término "performático". 
experiencia coincidiera con la incapacidad de contar. La tensión entre relato (representación) y acontecimiento como operación que ejecuta la performance la hace ingresar en una perspectiva histórica del arte. La performance, como práctica artística, se inscribe, de este modo, en eso que de forma tan lúcida ya advirtiera Feral en los 80: la pulsión de muerte del sujeto con todo su correlato de posmodernidad. Así pues pensar el relato, en este sentido amplio, sería otra forma de dar cuenta de la condición fracturada de la subjetividad contemporánea en la que la performance y los recursos performativos cabría entenderlos como aparatos de subjetivación que propenden o a su crítica o a la producción de nuevas subjetividades.

Pero es la propia concepción de relato la que sufre una expansión y alteración al pasar por el foco de la performatividad. Relato, aquí, menciona el suceder material de esa secuencia de incidentes que es aquello que presenciamos como "espectadores" de una performance. Sin duda el relato desde esta dimensión performativa es indisoluble del cuerpo quien lo ejecuta y lo carga en cierto modo. Por ello es que la performance se inscribe como un tipo de arte corporal. Sin embargo, si bien lo que acontece durante una performance es el cuerpo, éste sobre todo sucede en y como acción. La performance no exhibe al cuerpo en tanto presencia inerte y visual, sino en cuanto sujeto de acción, y a través de ello pone de manifiesto una determinada política del mismo. La performance no trata sobre el cuerpo como si de un tópico o de un ejemplo de algo se tratase. Al hacerlo accionar devela su inseparable calidad representacional. Una política del cuerpo se devela cuando éstos fallan sobre la escena, cuando se tensionan en relación a un relato que los intenta contener, es decir, cuando el cuerpo es pensado desde su condición temporal y no solo espacial. Los cuerpos duran, porque las acciones que ejecutan duran. Los cuerpos nos aparecen radicalmente materiales porque hacen y se someten a trabajos de resistencia cuyo indicador es el tiempo, pero el tiempo en cualquier realización escénica sucede a menudo desde una determinada economía que reparte en secuencias o diagramas: esto es mediante un relato, es por esto que la pregunta por la dimensión performativa es inseparable de la pregunta por el estatuto del relato, y aquello cuaja en el arte escénico cuando pregunto por la dramaturgia. De ahora en adelante cabría comprender la noción de dramaturgia en la lógica del campo expandido como la función de relato de un evento performativo, pudiendo estar esta función más cerca de u grado cero (sería el caso del performance art) o completamente convencionalizada (sería el caso de una puesta en escena clásica de un drama moderno). Performance y relato son pues, las dos dimensiones que constituyen una experiencia escénica. 